\title{
Gestão, desenvolvimento e êxito: Sociogénese da literatura de auto-ajuda em Portugal
}

Management, Development and Success: The Sociogenesis of Self-help Literature in Portugal

Gestion, développement et succès : sociogenèse de la littérature d'auto-assistance au Portugal

Fernando Ampudia de Haro

\section{(2) OpenEdition}

\section{Journals}

Edição electrónica

URL: http://journals.openedition.org/rccs/1511

DOI: $10.4000 /$ rccs. 1511

ISSN: 2182-7435

\section{Editora}

Centro de Estudos Sociais da Universidade de Coimbra

Edição impressa

Data de publição: 1 Setembro 2011

Paginação: 41-61

ISSN: 0254-1106

\section{Refêrencia eletrónica}

Fernando Ampudia de Haro, « Gestão, desenvolvimento e êxito: Sociogénese da literatura de auto-ajuda em Portugal », Revista Crítica de Ciências Sociais [Online], 94 | 2011, colocado online no dia 01 outubro 2012, criado a 04 maio 2019. URL : http://journals.openedition.org/rccs/1511 ; DOI :

$10.4000 /$ rccs. 1511

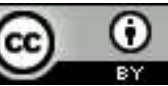




\section{FERNANDO AMPUDIA DE HARO}

\section{Gestão, desenvolvimento e êxito: Sociogénese da literatura de auto-ajuda em Portugal}

O objectivo deste artigo é analisar o código de comportamento e de emocionalidade que nasce da literatura de auto-ajuda publicada em Portugal a partir dos anos 1950, momento em que este tipo de publicações começa a ganhar presença e visibilidade. Inicialmente, este código parece afastar-se dos preceitos tradicionais defendidos pelo Estado Novo. No entanto, a análise da sua base social - o desenvolvimento económico, a integração do país no circuito capitalista internacional, a constituição da empresa como novo centro de integração social, a presença de novas mentalidades tecnocráticas e a procura, por parte do poder político, de um tipo de legitimidade baseada no desempenho - permite avaliar melhor esse eventual "afastamento" para observar como o regime integrou e assumiu a nova cultura comportamental e emocional da auto-ajuda num complexo produto de autoridade e liberdade. Tomando como referência os teóricos neofoucaltianos da governamentalidade analisa-se, através do exemplo da auto-ajuda, essa combinação de racionalidade política liberal e autoritária que o Estado Novo exibiu nos seus últimos vinte anos.

Palavras-chave: auto-ajuda; Estado Novo; governamentalidade; ideologia; literatura de auto-ajuda; Portugal; psicologia do comportamento.

Nos dias de hoje, as publicações de auto-ajuda proliferam em livrarias, centros comerciais, aeroportos, estações de comboio, áreas de serviço, quiosques e bibliotecas. Contrariamente ao sugerido há uns tempos no Diário de Notícias, ${ }^{1}$ a auto-ajuda é um fenómeno bem visível e, por acréscimo, acessível a um vasto grupo de cidadãos. É justamente sobre esse passado que se debruçam as páginas que se seguem.

O objectivo deste artigo é efectuar uma análise do código de comportamento e de emocionalidade configurado pelos textos de auto-ajuda publicados em Portugal durante as duas últimas décadas do Estado Novo. A análise não fica limitada aos próprios textos e procura ir mais além,

1 “Auto-ajuda, um fenómeno invisível”, Diário de Notícias, 23 de Maio de 2010. 
estudando a base social desse código construído segundo os preceitos da auto-ajuda. Trata-se, pois, de explorar a relação entre os textos, os códigos que propõem e as tendências sociais que, por um lado, criam as condições de possibilidade da auto-ajuda e que, por outro, são reforçadas e alimentadas por ela. A análise que proponho não passa por um estudo sistemático do fenómeno da auto-ajuda e da sua relação estrutural com a sociedade. O meu propósito é antes apresentar as afinidades electivas entre a auto-ajuda e as condições socioeconómicas associadas ao processo de desenvolvimento e modernização português. ${ }^{2}$ Sendo assim, o que interessa nestas páginas é observar as intersecções entre os modelos de comportamento e de emocionalidade derivados da auto-ajuda e a cultura do capitalismo industrial e empresarial.

De acordo com isto, num primeiro momento será realizada uma caracterização sintética do género da auto-ajuda, apresentando também os textos que serão analisados. Num segundo momento proceder-se-á à reconstrução do código de conduta e de emocionalidade que nasce destes textos, analisando em paralelo os argumentos que justificam o programa de comportamento que prescrevem. Como tal, a auto-ajuda desenha um modelo de indivíduo especialmente vinculado ao "êxito" numa dupla vertente psicológica e profissional. Numa secção final, esse modelo humano vai ser analisado sob uma perspectiva neofoucaltiana como expressão de uma modalidade específica de racionalidade política que se manifesta em diferentes fenómenos sociais dos anos 1960 e 1970 e que são afins à emergência da literatura de auto-ajuda em Portugal. ${ }^{3}$

\section{Auto-ajuda: características gerais}

A literatura de auto-ajuda constrói, através de conselhos e recomendações, programas de regulação comportamental emocional de carácter reflexivo conducentes a uma hipotética melhoria das condições psíquicas do indivíduo e à sua adequada adaptação ao contexto social em que vive. Estes programas conformam um código de conduta em função do qual as pessoas são socializadas segundo pautas tidas como aptas para a vida social. Esse código, por sua vez, constitui uma referência para a orientação do comportamento e da afectividade, circunstância que permite a integração do indivíduo nos padrões de actuação específicos do seu meio social.

\footnotetext{
2 Para uma aproximação ao conceito de afinidade electiva, ver Lamo de Espinosa et al. (1994: 264-278).

${ }^{3}$ Para uma aplicação deste esquema de análise ao caso espanhol, ver Ampudia de Haro (2010a).
} 
Como género, a literatura de auto-ajuda centra-se, globalmente, na dimensão subjectiva da pessoa: é este o ponto de arranque a partir do qual se persegue uma mudança vital que seja considerada satisfatória pelo indivíduo. Assim, a auto-ajuda serve-se de diferentes recursos retóricos, sendo os mais frequentes: a) a utilização do "tu" ou do "nós" inclusivo; b) a repetição redundante das ideias principais; c) a exemplificação a partir de situações reais e testemunhos pessoais; d) o diagnóstico interactivo mediante testes e provas; e) a atribuição ao leitor da capacidade definitiva para modificar as suas condiçõos comportamentais e emocionais. ${ }^{4}$ Por outro lado, a estrutura expositiva mais habitual remete, inicialmente, para a tipificação do problema ou da situação que se tenciona modificar para, posteriormente, aplicar as prescrições e soluções de acordo com o discurso legitimador que as justifica.

Apesar de tudo, as fronteiras do género não são impermeáveis, o que explica a existência de um espaço relativamente difuso no qual se localizam publicações que, embora não possuam todas as características paradigmáticas da literatura de auto-ajuda, partilham com ela certos elementos e afinidades. Neste espaço podemos encontrar romances, biografias, memórias, ou textos de pensamento oriental, medicinas alternativas ou controlo corporal. Nestas coordenadas enquadram-se os textos que aqui vão ser analisados, cumprindo todos eles, na sua forma e conteúdo, os requisitos estabelecidos para definir o género da auto-ajuda. Isto não significa que não apresentem diferenças entre si que salientem a sua singularidade. Não obstante, tais diferenças são atenuadas e ultrapassadas pela sua coerência temática, expositiva e retórica. Ainda hoje não dispomos de dados suficientes que nos permitam conhecer exactamente o seu grau de difusão ou o leitor-tipo que recorre a elas. Apesar disto, o número de edições e reedições proporciona algumas pistas sobre a presença da auto-ajuda em Portugal, muito embora fosse necessária uma pesquisa mais aprofundada sobre esta matéria.

Em seguida, são apresentados alguns dos textos analisados nestas páginas: - Como fazer amigos e influenciar as pessoas ([1936] 1952), de Dale Carnegie. Desde a sua publicação em 1936 vendeu, até hoje, mais de 15 milhões de exemplares em todo o mundo. É, sem dúvida, um dos textos fundadores e, em grande medida, a obra que vai fixar muitas das características típicas do género. Utilizo aqui a primeira edição portuguesa (1952), à qual se seguiram mais catorze edições até 1994. Segundo Carnegie, a sua intenção foi a de escrever um livro que ainda não existia. Para isso, baseou-se na sua experiência como formador e consultor, nas contribuições de diferentes psicólogos, nas biografias de personagens como Júlio César ou Edison

\footnotetext{
${ }^{4}$ Para uma caracterização sistemática e precisa do género, ver Papalini (2008).
} 
ou em entrevistas com personagens como Marconi, Franklin D. Roosevelt ou Clark Gable. Em síntese, este texto representa um guia para aumentar o poder da simpatia, da influência e do prestígio.

- Ajuda-te a ti mesmo ([1910] 1926), de Orison Swett Marden. Outro dos autores de referência, esteve estreitamente vinculado ao New Thought Movement, corrente ecléctica que apostava numa modalidade de pensamento positivo como motor da acção humana. Emprego aqui a primeira edição portuguesa, reeditada em 1944 e 1957. Marden foi, certamente, um autor prolífico: na Biblioteca Nacional existem 116 registos das suas obras, publicadas ininterruptamente em Portugal desde os anos 1930 até aos anos 1970. Eis um texto clássico à volta do conceito de auto-ajuda como mobilização da energia do pensamento para a concretização de metas individuais.

- Mandamentos da saúde, da civilidade, do triunfo (1945), de F. Pereira Rodrigues. Exemplo de texto elaborado, neste caso por um autor português, segundo o método da intertextualidade, ou seja, recolhendo fragmentos e citações dos autores de referência na matéria. Carnegie e Marden são uma presença constante nas suas páginas, assim como os testemunhos de consultores e gestores de empresas norte-americanas. Pensado como manual que pode ser consultado segundo diversas secções temáticas, constitui uma interessante amostra da recepção da auto-ajuda em Portugal.

- Como triunfar no comércio (1953), de J. Fontana da Silveira. O autor oferece uma extensa variedade de conselhos de orientação para a vida empresarial, entendida esta como uma síntese de arte e de técnica, capaz de gerar prosperidade material, mas também de activar os recursos próprios de uma vontade criadora. As referências a Marden são constantes e inclui o habitual decálogo para obter sucesso nas vendas - "Os 10 Mandamentos do Comerciante" - prática comum neste género de publicações.

- A força do pensamento na vida e nos negócios ([1900] 1950) de William Walker Atkinson. Esta obra desenvolve uma linha argumental centrada na importância do pensamento como fonte de inspiração da conduta e como ferramenta de influência sobre terceiros.

- A arte de triunfar ([1933] 1942), de Maurice Torfs. Nas suas páginas, pretende-se realizar uma extrapolação do conceito de "eficiência" para a vida pessoal. O autor resgata esse conceito da "ciência dos negócios" para tentar a sua aplicação no quotidiano. Assim, a "eficiência" levaria à eliminação da "sorte" como factor de sucesso para, em troca, ser substituída pelo potencial criador de cada pessoa.

- Como melhor viver e ganhar mais dinheiro (1961), de Francisco Ramalho. Baseando-se em muitas das ideias de Carnegie, o autor redige um manual em torno da noção de triunfo como resultado da activação da força interior pessoal. 


\section{O homem de êxito}

O objectivo da literatura de auto-ajuda e do código de conduta que prescreve é o desenvolvimento de uma modalidade de pensamento criativo capaz, quando levado à prática, de transformar a vida da pessoa. Essa transformação comporta a elaboração de um programa de vida estritamente individual: "Se não tens uma casa, junta os tijolos para a fazer, e se não tens tijolos, desenha-a sobre o papel. Cada homem deve ter uma ideia, um projecto, um desenho" (Rodrigues, 1945: 123). Este projecto tem uma razão de ser, não outra que alcançar a plenitude psíquica, entendida como amálgama de prestígio, prosperidade e sucesso pessoal e que, de uma forma geral, pode ser identificada com a felicidade. Contudo, não existe uma definição unívoca dessa felicidade, visto que a auto-ajuda apenas abre caminhos ou aponta possibilidades: a sua vocação é pretensamente não normativa, dado que opta, pelo menos retoricamente, por sugerir e recomendar.

Mas qual é o ponto de partida na perseguição desse objectivo? O reconhecimento e o treino da "força de pensamento" (Marden, 1926: 144; Atkinson, 1950: 16), das "forças mentais" (Marden, 1926: 145), da "força interior" ou das "forças ocultas da vontade" (Ramalho, 1961: 3). Estamos perante um caudal de energia, um vigor individual que leva, através da mente, à acção. É a mente o motor da actividade e a primeira causa que determina qualquer linha de actuação. Neste terreno, a auto-ajuda tem por missão fornecer as ferramentas para a activação desse ímpeto mental que alimenta o comportamento. Como afirma Carnegie (1952: 23), "têm mágico efeito" revolucionando "por completo a vida de muita gente". A intenção é "apresentar um manual deveras eficiente, redigido de molde a ser compreendido por todos os portugueses, no intuito de mostrar que todos temos dentro de nós qualquer coisa adormecida que, posta em evidência, nos dará resultados deveras surpreendentes" (Ramalho, 1961: 3).

Daí que a auto-ajuda estabeleça uma metodologia de utilização: rever cada capítulo, interromper a leitura para reflectir sobre o que já foi lido, sublinhar o mais relevante ou anotar as situações em que foram aplicados os seus conselhos são as mais comuns destas "instruções de uso". A consulta destes textos deve ser um hábito, pois em virtude deles a pessoa saberá como comportar-se: "Todas as vezes que se encontrar em face de um problema específico $[\ldots]$ hesite em fazer o que seu impulso lhe aconselha. A maior parte das vezes é um erro. Volte-se antes para estas páginas e reveja os parágrafos que sublinhou" (Carnegie, 1952: 65). Cumprindo com estes procedimentos, o indivíduo deve proceder à realização de um exercício de auto-sugestão que o ajude na descoberta e na activação da sua força mental: "Nada sucede sem que a mente o provoque. Nada surge neste mundo 
sem que o pensamento preceda à acção. O pensamento move tudo [...] É a força inicial de todos os movimentos, de todas as empresas, de todos os êxitos" (Marden, 1926: 144). Esta manobra de auto-sugestão constitui, simultaneamente, um exercício de auto-ajuda. O indivíduo, desdobrado reflexivamente, é o objecto que há-de ser ajudado, bem como o sujeito que fornece a ajuda; a pessoa, tomando conta de si própria, converte-se na variável fulcral da qual depende a realização das suas aspirações. Apesar de tudo, não está sozinha neste processo e Deus é também um pilar de apoio sempre e quando cada um de nós seja capaz de se ajudar: "[...] o Deus supremo, com toda a sua Omnipotência, não pode, nem quer nem deve ajudar a quem não se ajuda a si mesmo" (ibidem: 280).

Portanto, o primeiro passo é a auto-sugestão que leva ao arranque da energia inspiradora da acção. Situamo-nos perante um indivíduo que diz "eu posso, eu quero" ou que "vai para adiante": quem afirmar "não posso" só pode fracassar. Nesta altura, a razão do fracasso é bem conhecida: "Vós sabeis que esta é a verdade. Mas perguntais-me a causa d'esta differença? Está simplesmente no pensamento, só no pensamento de cada dia" (Atkinson, 1950: 16). É algo tão simples quanto "pôr em prática as forças ocultas da nossa vontade" (Ramalho, 1961: 12). A auto-sugestão como descoberta da força de pensamento e a sua identificação como motor da acção conformam o fundamento do êxito. Mas o que é ter êxito?

Ter êxito, para a auto-ajuda, é sinónimo de concretização de um plano individual original que afirme a confiança nas próprias possibilidades e na vontade, que alimente o reconhecimento dos outros e que traga consigo um aumento da prosperidade pessoal. Aqui, os textos vão escolher os negócios, as vendas ou, de forma genérica, a actividade económico-empresarial como espaço prioritário para a consecução do êxito. Eis o âmbito privilegiado de actuação para o homem bem-sucedido, medido, substancialmente, em termos profissionais num contexto de concorrência crescente: "No mundo de hoje não há lugar para os enfraquecidos [...] possuímos armas perante as quais nos podemos elevar, triunfar como todos os que desenvolveram o poder da vontade triunfaram e se distinguiram". A prova disto "são os inúmeros casos de tantos homens que começaram desde baixo numa empresa até se tornarem empregados superiores, gerentes, sócios e até únicos proprietários" (ibidem: 14). No fundo, isto não é mais do que uma inevitável manifestação da natureza humana, pois " a igualdade é e sempre será uma fórmula. Poderá tentar-se a sua realização por leis artificiais; a lei natural acabará sempre por triunfar" (Torfs, 1942: 25). Por outras palavras, o êxito passa por "não aceitar uma vida de subalternidade" (Rodrigues, 1945: 137), pelo "desejo de sobressair", pelo "desafio", por "vencer o competidor" 
ou por "sair da fila" (Torfs, 1942: 32). Com esta finalidade, o indivíduo à procura de êxito deve reunir qualidades tanto técnicas como psicológicas.

No que respeita às qualidades técnicas, será necessário acompanhar o ritmo das mudanças e dos tempos, conhecendo as características dos concorrentes, visitando exposições e mercados, lendo publicações especializadas, frequentando cursos e palestras e aumentando os conhecimentos de cultura geral (Silveira, 1953: 22); em suma, tudo o que permitir "renovar o sangue nas artérias do teu negócio" (Marden, 1926: 155). No que toca às qualidades psicológicas, os textos insistem na sua extrema importância, assim como na sua aquisição mediante a aprendizagem e a prática de acordo com os conhecimentos que proporciona a psicologia como disciplina científica. Estas qualidades são imprescindíveis para a consecução das metas pessoais. Como aponta Carnegie (1952: 20), 15\% do sucesso financeiro deve-se ao conhecimento técnico profissional e $85 \%$ depende da "engenharia humana", do "conhecimento da psicologia humana e das suas faculdades" (Silveira, 1953: 42). A esse respeito, a primeira dessas qualidades é conhecer-se a si próprio como requisito para desenvolver uma atitude optimista e favorável à inovação; uma atitude corajosa, decidida e com iniciativa (ibidem: 12). Além disto, o conhecimento da psicologia humana é fundamental como meio de relacionamento com as outras pessoas $\mathrm{e}$, mais especificamente, como recurso para as influenciar acomodando a sua vontade aos interesses próprios. Por este motivo, a auto-ajuda outorga a máxima atenção a essa gestão da conduta alheia mediante a capacidade de sugestão: "Se quer persuadir alguém a fazer alguma coisa, antes de abordar o assunto, faça a si próprio a seguinte pergunta: Como poderei fazer com que ele queira isto?” (Carnegie, 1952: 51). A resposta a esta questão passa pela consideração do factor "interesse": "O êxito depende em boa parte da nossa habilidade em inspirar interesse aos outros homens, em os atrair para influenciá-los" (Atkinson, 1950: 24). Para ter acesso aos interesses alheios, será necessária uma abordagem empática da outra pessoa, "ver as coisas pelo seu ângulo" (Carnegie, 1952: 60), tratá-la pelo nome, encorajá-la a falar em si própria: o homem cortês, simpático e capaz de atrair o interesse alheio é quem reúne mais hipóteses de sucesso (Torfs, 1942: 69) ou, por outras palavras, quem descobre o "lado fraco das pessoas" e as conduz por esse meio (Rodrigues, 1945: 139).

A capacidade de influência e sugestão habilita para o empreendimento de negócios, mas também para a liderança ou a chefia de grupos de pessoas. Se, como já foi dito, o homem de êxito recusa viver uma vida de subalternidade, o certo é que parece mais vocacionado para o desempenho de tarefas directivas com, precisamente, subalternos sob o seu comando. Essas tarefas 
requerem um espírito jovial, prudência, evitar um excesso de familiaridade que leve à perda da autoridade e à não anulação do entusiasmo mediante um tratamento "áspero ou bruto" (ibidem: 140). Mas também prestar atenção às "modernas fórmulas de relações entre empregados e patrões", tentando estabelecer uma "ponte de passagem", para que todos percebam as necessidades de todos e evitar assim os conflitos (Silveira, 1953: 44).

Em conclusão, estamos perante um código de regulação comportamental e emocional que indica qual o caminho para o êxito, convertendo a actividade empresarial no palco privilegiado de aplicação desse código. Ao fim e ao cabo, "a vida comercial reúne em si todas as possibilidades para assegurar o bom êxito aos que desejam triunfar na vida" (ibidem: 116). Um código que, construído a partir da auto-ajuda, promove a "contínua ascensão" quando ao indivíduo "se lhe afigure ser impossível maior prosperidade" (Marden, 1926: 155). A pessoa é obrigada a insurgir-se contra "o preconceito estabelecido há séculos, o qual supõe incompatibilidade entre a honra e o proveito, entre os negócios mundanos e a vida espiritual" (ibidem: 157). Não em vão, "ganhar dinheiro pode ser um dos mais belos desportos, e dos mais honrosos" (Torfs, 1933: 106).

\subsection{As lógicas do êxito}

O código que prescreve a auto-ajuda orienta-se para um êxito que parte do domínio psicológico e que se concretiza no plano profissional. Existem duas lógicas que governam as suas prescrições: uma primeira de cariz expressivo e uma outra de natureza utilitária (Bellah et al., 1989: 54-58, 394-395).

A lógica expressiva centra-se na reivindicação da força interior pessoal como núcleo que define a individualidade e o autoconhecimento da própria subjectividade. Essa subjectividade, que é pessoal e por isso original, constitui a base a partir da qual a pessoa interpreta a sua actividade no mundo social. Isto é, os efeitos do desenvolvimento da força interior não se esgotam no universo privado da pessoa, mas vão mais além para explicar a dimensão pública do indivíduo. Esta vertente pública é identificada com o trabalho e a actividade comercial-empresarial. Tal actividade é seleccionada pela auto-ajuda para mostrar que o êxito não é só desenvolvimento da subjectividade individual, como também um desenvolvimento aplicável ao mundo empresarial. Neste ponto, dá-se uma intersecção da lógica expressiva com uma lógica utilitária, vinculada à noção de satisfação dos interesses pessoais conforme os objectivos e as preferências individuais. Conceitos como "sugestão alheia" ou "captação do interesse" remetem para uma canalização da conduta alheia segundo a conveniência particular. Carnegie, por exemplo, com recurso ao livro How to Turn People into Gold, de Kenneth M. Goode (1929), faz uma 
síntese do argumento da utilidade, na qual reconhece o interesse individual como razão da acção humana, outorgando à sugestão a potencialidade de moldar o interesse alheio:

Detenha-se por um momento para comparar o seu profundo interesse pelos negócios e o seu superficial interesse por tudo o mais. Saiba que todos no mundo pensam exactamente da mesma maneira [...] em suma, o êxito em tratar com as pessoas depende da simpática apreensão do ponto de vista alheio. (Carnegie, 1952: 167)

A utilidade que deriva da persuasão alheia não é apresentada estritamente como uma forma de manipulação estratégica do outro, mas sim como o efeito que gera a capacidade de atracção sobre os outros; isto é, o produto da expansão de uma subjectividade individual capaz de liderar e conduzir iniciativas. Temos, pois, um entrelaçamento da expressividade e da utilidade na auto-ajuda num código que aposta na construção de um perfil humano que combina o vocabulário da psicologia - afim à expressividade - com o vocabulário da economia, do lado da utilidade. $A$ arte de triunfar de Torfs é um bom exemplo desta combinação. Retira o conceito de eficiência do domínio da economia para o tornar mais abrangente, atribuindo-lhe um significado vital: "O homem eficiente é aquele que arranca à existência a maior porção do que ela lhe pode fornecer". Uma vez ampliado o significado, o autor procede à sua redefinição, desta vez ligada à componente subjectiva da pessoa: "A eficiência é profundamente humana. Confundiram-na durante muito tempo com a noção de 'business' americano. É como o dia e a noite. A base da eficiência é o sentimento. É por ele que havereis de vencer" (Torfs, 1942: 12).

Mediante a lógica da expressividade e da utilidade ou, dito de outra forma, mediante o vocabulário da psicologia e da economia, a auto-ajuda promove um estilo emocional (Illouz, 2007: 16-20), ou seja, a formulação de uma imaginação interpessoal, uma modalidade de pensamento acerca do "eu" e das suas relações com o "alter". No que aqui interessa, este estilo emocional inscreve-se genericamente num contexto social de liberalização económica no qual a empresa se destaca como novo centro de integração social. A expansão da empresa traz consigo, ao mesmo tempo, a difusão das teorias da administração e da organização, a crescente notoriedade da figura do gestor-empreendedor e a valorização do conhecimento científico sobre as emoções e as suas relações com a produtividade e a eficácia. Em resumo, dois saberes, a psicologia e a economia, que nas suas concepções mais genéricas, estabelecem as coordenadas para a regulação comportamental e afectiva individual. Interessa pois, nas páginas seguintes, questionar o porquê desses saberes, isto é, indagar sobre as bases sociais do êxito. 


\section{A base social do êxito}

Num outro artigo (Ampudia de Haro, 2006) defendi que a literatura de auto-ajuda constitui uma das manifestações da racionalidade política liberal. Esta racionalidade, no seu exercício do poder, concebe os indivíduos como sujeitos capazes de se autogovernarem e preconiza uma economização desse exercício, procurando que a pessoa mobilize a sua própria energia em prol do seu autogoverno. ${ }^{5}$ Uma afirmação desta natureza pode resultar paradoxal, se tivermos em conta que os textos analisados nestas páginas foram publicados durante o Estado Novo. A priori, como sistema autoritário, o regime negaria esse eventual autogoverno, optando por um exercício do poder mais coactivo ou repressivo e com uma margem quase nula para a iniciativa individual. Sob esta perspectiva, a auto-ajuda integrar-se-ia num contexto geral de racionalidade política autoritária - encarnada no sistema "estadonovista" - que pressuporia nos seus governados uma incapacidade global de autogoverno. O autoritarismo salazarista e marcelista conceberia assim a sua acção de governo sob uma óptica disciplinar, que implicaria a correcção ou a conversão dos indivíduos vencendo as suas resistências e submetendo-os a um padrão de comportamento fixo e unívoco. ${ }^{6}$ Como compatibilizar, portanto, o autoritarismo com a suposta confiança na capacidade de autogoverno pessoal que promete o código do êxito?

A presença da auto-ajuda durante o Estado Novo talvez possa constituir um indicador da coexistência compatível entre racionalidades políticas autoritárias e liberais; compatibilidade essa que prova a complexidade das relações entre a liberdade e o poder e que nos convida a enriquecer a análise sobre o poder para além da tradicional dicotomia dominação/resistência. A noção de racionalidade política, de inspiração foucaltiana, pode contribuir para esse enriquecimento. Com ela, designamos os objectivos de qualquer tipo que são perseguidos no exercício do poder, os princípios teóricos e filosóficos em nome dos quais são definidos tais objectivos e a concepção que se possui acerca da natureza dos sujeitos governados (Rose e Miller, 1992: 178; Marinis 1999: 87-88). Ao centrar estas páginas nos modelos de comportamento e de emocionalidade que moldam um arquétipo de êxito, a minha análise vai-se concentrar nessa terceira dimensão relativa à natureza atribuída aos sujeitos governados.

Retomo agora o paradoxo que antes formulava: Como articular no contexto "estadonovista" a aposta no autogoverno da auto-ajuda? Há muito

\footnotetext{
5 Para uma definição do conceito de racionalidade política, ver Burchell (1993: 289), Rose (1997: 27), Marinis (1999: 77) ou Hyndess (1997: 103).

${ }^{6}$ Acerca desses padrões de correcção e conversão, ver Ampudia de Haro (2010b).
} 
tempo que os estudos sobre governamentalidade (governmentality studies), isto é, aqueles que fazem do conceito de racionalidade política o seu eixo, insistem na presença de componentes autoritárias nas formas de governo liberais (Valverde, 1996; Dean, 2002). Essas componentes relacionam-se com certos espaços e momentos nos quais é suspenso o exercício da liberdade que a racionalidade liberal pressupõe no indivíduo. ${ }^{7}$ Segundo a óptica da governamentalidade, o liberalismo não é uma doutrina ou uma filosofia política, mas sim uma maneira de conduzir condutas que tem presente a iniciativa do governado para a reconduzir de acordo com os objectivos de governo. Sabendo, pois, que o liberalismo inclui mecanismos autoritários de governo, podemos concluir que as diferenças entre um governo liberal e um outro autoritário não são diferenças de incomensurabilidade substancial e sim de grau (Vázquez García, 2005: 193). A lógica comummente empregue nos estudos de governamentalidade incide na detecção de mentalidades e procedimentos autoritários em contextos formalmente admitidos como liberal-democráticos. No entanto, quero aqui aplicar a lógica contrária: detectar e analisar racionalidades políticas liberais em contextos reconhecidos formalmente como autoritários, servindo-me, para essa finalidade, da auto-ajuda e do Estado Novo. Nesta linha, julgo ser no espaço genérico da actividade económico-empresarial que podem ser encontradas as manifestações mais evidentes de uma racionalidade política liberal e, por conseguinte, é também neste espaço que se encontram as variáveis que vão permitir a compreensão do fundamento social da auto-ajuda. Procurarei identificar os fenómenos e tendências que apontam para a configuração de racionalidades liberais de governo, as quais estão estreitamente vinculadas às linguagens da psicologia e da economia e, simultaneamente, são afins aos pressupostos da auto-ajuda.

Entre tais fenómenos e tendências, é fundamental salientar o desenvolvimento de formas e mentalidades tecnocráticas desde os anos 1950, mais consolidadas a partir dos anos 1960, com uma visão e procedimentos específicos no terreno da administração e da gestão pública e privada. A tecnocracia defende a possibilidade de aplicar a razão científica nesse terreno, concretizada em saberes tidos como objectivos (engenharia, economia, psicologia, sociologia...). Tais saberes serão considerados imprescindíveis para a implementação de diferentes medidas e iniciativas que levem à modernização socioeconómica do país. A partir dos mesmos, também será

\footnotetext{
${ }^{7}$ Como aponta Vázquez García (2005: 13), estratégias de cariz autoritário em regimes oficialmente liberais podem surgir em contextos de guerras, aumento da criminalidade, imigração ou acções terroristas. Mas nem sempre é necessário esse grau de excepcionalidade: basta pensar nas medidas de eugenia e higiene racial aplicadas em democracias liberais desenvolvidas, como os EUA ou a Suécia.
} 
estabelecida uma analogia entre o Estado e a empresa: do mesmo modo que o empresário gere conforme um conhecimento económico-gerencial, o Estado pode ser gerido de acordo com pressupostos similares de eficácia. É precisamente o Estado o agente que surge como supervisor do desenvolvimento e da modernização, reorganizando as suas estruturas e os seus propósitos de acordo com critérios instrumentais e racionais. O discurso oficial vai falar, neste sentido, na "modernização administrativa", na "reforma e racionalização das estruturas básicas que enquadram a vida administrativa e financeira", na "aplicação coerente e eficaz dos recursos" 8 ou na tentativa de "corresponder às necessidades e às exigências de uma administração moderna e eficaz". ${ }^{9}$ O objectivo era, segundo Pinto Leite, a ocupação das funções superiores da administração por pessoas "com uma preparação técnica de alto nível", cargos "modernos e realizadores que com o maior patriotismo se esforçam por acelerar o ritmo de desenvolvimento económico e social deste país" (apud Fernandes, 2005: 84).

Não obstante, isto não implica que esta concepção do Estado venha substituir totalmente uma outra concepção, a do Estado-polícia, guiado por um tipo de racionalidade substancial assente em valores e princípios morais e ideológicos, na qual assentavam elementos tão definitórios do Estado Novo como, por exemplo, a repressão da oposição ou a defesa da nação portuguesa na guerra colonial. Há, pois, uma coexistência das concepções modernizante e tradicional do Estado, bem sintetizada nas seguintes palavras de João Cravinho, na alusão à reforma da administração dos serviços públicos:

Perante um movimento que de dia a dia ganha força, há quem pretenda reorganizá-los segundo métodos mais modernos, mas sem pôr em causa hábitos velhos e posições adquiridas, cujo repúdio aberto, franco, repugna ainda à mentalidade vigente. Trata-se de mais uma manifestação do que tem sido designado por modernismo tradicionalista, agora no âmbito da Administração e, também, dizem-me, das empresas. (Cravinho, 1969: 439)

A mentalidade tecnocrática constitui uma reformulação da tradicional perspectiva contra-revolucionária da direita portuguesa, adoptando um novo conservadorismo baseado nos avanços técnico-económicos e na adopção de um intervencionismo estatal activo na economia junto com o reconhecimento da livre iniciativa individual nos mercados. É um tipo

\footnotetext{
${ }^{8}$ Pinto Leite apud Fernandes (2005: 50), em nota enviada a Melo e Castro.

9 Almeida Cotta, apud Fernandes (2005: 86).
} 
de mentalidade que se autodefine como apolítica e que participa de uma crença no fim das ideologias como critério de governo, substituídas por critérios técnico-científicos supostamente objectivos e neutros. Assim, a acção de governo não é percebida como política e sim como um procedimento essencialmente técnico. As palavras de Xavier Pintado, referindo o seu trabalho como Secretário-Geral de Comércio, servem como ilustração deste fenómeno:

Tudo isto se procura fazer bastante tecnocraticamente, isto é, bem, racionalmente, e não politicamente no sentido de olhar os ventos e ver para onde sopram. Que o que se faz possa permanecer e produzir resultados hoje e sobretudo amanhã para o futuro do País, é a grande ambição que se prossegue... O que se fez, se melhor não se fez foi porque se não soube: nunca por receio, cálculo a ânsia de popularidade. (apud Lyra Passos, 1990: 639)

Estes critérios tecnocráticos de gestão e administração são tidos como critérios válidos independentemente da natureza do órgão ou da instituição nos quais se aplicam, e intercambiáveis ou transponíveis entre o Estado e a empresa. Desta forma, ficava recolhida esta ideia, por exemplo, numa memória publicada no Boletim da Ordem dos Engenheiros em 1955: "A conclusão a tirar acerca da política económica das empresas e das nações é que, afinal, esta política é a mesma, cada uma no seu campo de acção" (apud Brito, 1989: 233).

A difusão desta mentalidade tecnocrática é também afim à reivindicação por parte do Estado Novo de uma legitimidade baseada no desempenho, ou seja, nas suas realizações práticas (infraestruturas, segurança...) e na elevação do nível material de vida dos portugueses, argumento mediante o qual se asseguraria a adesão dos cidadãos e a sua desmobilização, uma vez garantido um dado patamar de bem-estar. Um modo, pois, de difusão do cepticismo político: os portugueses, se continuassem a melhorar materialmente, não teriam nem tempo, e o que era mais importante, nem motivos para se envolverem na política. Pinto Leite traçava um paralelismo com a Alemanha Ocidental num artigo de 1965 na revista O tempo e o modo:

Os alemães ocidentais vivem hoje materialmente bem. Não existe desemprego [...] os salários e ordenados permitem um nível de vida elevado, enfim, o cidadão normal tem a barriga cheia, a casa aquecida, veste e calça bem, tem automóvel e televisão, faz três semanas de férias nas praias do sul, trabalha muito e tem pouco tempo para se dedicar à metafísica. (apud Fernandes, 2005: 35) 
Mas que dados suportam essa legitimidade de desempenho reclamada pelo Estado Novo? Entre 1960 e 1970, o PIB cresceu a uma taxa anual média de 6,1\% e de 7\% entre 1970 e 1973 (Durán Muñoz, 1997: 377). O rendimento por habitante também cresceu a uma média superior a $6,5 \%$ entre 1960 e 1973. O país viveu um processo de terciarização que envolveu um aumento dos funcionários estatais e a expansão das actividades comerciais, bancárias e de comunicações. O ensino superior tornava-se mais abrangente e as infraestruturas melhoravam. Aspectos que hoje podem ser considerados quase triviais - electricidade, água canalizada, ligação aos esgotos ou casa de banho nos lares portugueses - eram, na altura, novidades para amplos sectores da população, que começavam, desta maneira, a usufruir das suas vantagens. Em suma, como aponta Barreto (2004), perfilava-se uma incipiente sociedade de consumo com a incorporação ao quotidiano de bens como a televisão, o telefone, os electrodomésticos ou o carro. A generalização paulatina do bem-estar e do consumo foi entendida, em muitos sentidos, como um processo induzido por um Estado mais racional, eficiente e eficaz, que actuava como promotor da modernização do país. Não por acaso, a própria denominação de Estado Novo tendeu a ser substituída pela sua designação como Estado Social, aludindo à melhoria do bem-estar dos portugueses, propiciada pelas suas políticas.

O Estado assumiu a sua quota de protagonismo na modernização do país através de diferentes iniciativas. A 23 de Janeiro de 1959 era criado o Instituto Nacional de Investigação Industrial que, pelas palavras do seu director, Magalhães Ramos, era "a última tentativa para que o povo português actualize a sua maneira de trabalhar e de dirigir o trabalho" (apud Gonçalves, 1991: 107). Esta instituição teria como objectivo a promoção do desenvolvimento e da produtividade, mediante a formação de quadros superiores em matérias de gestão e organização do trabalho. Num contexto de necessidade de conhecimento técnico-científico, só pela via do desenvolvimento e da edificação de uma base económica sólida podia o país construir o seu futuro. Esta linha de pensamento ganhava visibilidade, por exemplo, três anos mais tarde, quando, no Congresso de Ensino de Engenharia (1962), uma das comunicações apresentadas vinha ratificar uma ideia similar: "Os povos com mais baixo nível de vida - e nós estamos infelizmente neste caso precisam mais da cultura científica do que artística, literária ou jurídica [...] Em suma, primeiro olhe-se ao que é economicamente mais importante, e neste caso, é a investigação nas ciências exactas e, sobretudo, nas aplicadas e nas suas bases" (apud Gonçalves, 1991: 120).

O Estado também não se esquece das linhas programáticas do desenvolvimento e procede ao seu planeamento. Como tal, foram elaborados 
sucessivos planos de fomento entre 1953 e 1973 que visavam enquadrar tal desenvolvimento, outorgando, na linha defendida pela OCDE, um papel de relevo à articulação entre as actividades produtivas e a formação do capital humano. Nesta linha, Pinto Leite insiste no carácter fulcral da ligação entre a economia e a formação: "Desenvolvimento económico e instrução andam a par [...] Todo o dinheiro gasto na educação é um investimento económico rentável" (apud Grácio, 1990: 233). Comprova-se que a variável 'economia' é uma das chaves-mestras da modernização de Portugal. Aos engenheiros, cuja participação vem de mais longe, unem-se os economistas como quadros técnicos e consultores do desenvolvimento e que têm contacto com as ideias procedentes do exterior, que conhecem o paradigma keynesiano e que acreditam no mercado e na livre iniciativa em conjunção com a acção estatal. Ulisses Cortês, Ministro de Economia, no seu discurso de encerramento do II Congresso dos Economistas e da Indústria Portuguesa (1957), resumia esta posição do seguinte modo:

A aç̧ão estatal deve consistir menos em investir directamente do que traçar orientações, propor finalidades, criar estimulantes fiscais, orientar o crédito e instituir as condições indirectas, quer económicas e financeiras, quer técnicas e culturais, que propiciem o desenvolvimento das iniciativas e o esforço criador dos particulares. (apud Rosas, 1994: 464)

Abre-se um espaço para a iniciativa privada na esfera económico-empresarial em paralelo à difusão das mentalidades tecnocráticas; livre iniciativa esta que não é no entanto reconhecida em âmbitos como o político como ilustrativo dessa coexistência entre racionalidades políticas liberais e autoritárias. E não é estranho que aconteça isto. A tecnocracia, apesar de defender a livre iniciativa, é tendencialmente autoritária, na medida em que se apoia no conhecimento técnico selectivo de uma elite que lidera a acção governativa e que impõe tal conhecimento como critério de acção: é a posse de determinados conhecimentos o que justifica a liderança, em contraposição à maior parte da população, que carece desses mesmos conhecimentos. Contudo, habilita-se esse espaço para o indivíduo exercitar a sua capacidade de autogoverno - o espaço genérico da actividade económica - orientada para o estabelecimento de prioridades, a escolha dos meios apropriados para as satisfazer e a maximização das suas utilidades; um indivíduo que age na sua qualidade de empreendedor - e aqui a auto-ajuda fornece esse arquétipo de êxito ligado ao empreendedorismo -, de capital humano - apostando na sua formação como via de promoção social -, ou de consumidor - manifestando a sua autonomia pessoal de compra. 
Em todo caso, o autogoverno na esfera económica não deve ser reduzido a um "cientificismo" que anule o peso dos factores emocionais em nome da razão. Nessa esfera há também espaço para a subjectividade individual, aberta por certas concepções da dimensão humana das organizações, da gestão das mesmas e do indivíduo como recurso produtivo mediado pela sua motivação. Face ao "cientificismo" ou ao "desenvolvimentismo", alçam-se as vozes que postulam uma modernização que não perca de vista o ser humano. Um dos discursos mais autorizados neste domínio é o do Adérito Sedas Nunes na sua crítica a uma concepção "tecnocratista" do desenvolvimento; um "tecnocratismo" entendido como sistema de análise e visão dos problemas sociais baseados no despojamento dos seus elementos emocionais ou na sua redução a um sistema operacional de teorias, conceitos e indicadores (Nunes, 1968: 324). Na sua opinião, existiria um consenso entre todas as posições ideológicas relativo à necessidade do desenvolvimento: "Não é se quisermos ser ricos, mas pura e simplesmente se quisermos ser, que temos de nos desenvolver" (ibidem: 267). Seria necessário imprimir um sentido humano a esse desenvolvimento, pois só assim é que se poderia falar em progresso. Note-se que Sedas Nunes articula o seu discurso sobre o sentido humano do desenvolvimento apoiado numa matriz cristã de pensamento ligada à doutrina social da Igreja. No entanto, não foi o único. As actas do II Encontro de Diplomados Católicos (1963), sob o título "Perspectivas Cristãs do Desenvolvimento", salientavam, entre os assistentes e intervenientes, "a competência científica e técnica de que deram provas, bem como o espírito cristão que a todos dominava" (Gonçalves, 2006: 382). Dois anos mais tarde, num Encontro de Engenheiros e Economistas Católicos voltava a ser afirmada a indispensabilidade de um acento cristão na formulação do desenvolvimento num país no qual uma grande parte da população vivia em condições "indignas de seres que dizemos filhos de Deus e irmãos nossos" (ibidem: 383 ).

Se o factor humano era posto em relevo a partir de um posicionamento cristão, dentro da empresa, esse factor foi reivindicado através da linguagem da psicologia. A crítica do "cientificismo" económico foi empreendida em nome da valorização da subjectividade individual, assumindo os pressupostos do enfoque das Relações Humanas nas organizações baseado nas contribuições de George Elton Mayo. Desta forma, a subjectividade individual, materializada nas emoções ou na motivação, é convertida numa variável fundamental da actividade económico-empresarial. Não obstante, a vindicação do factor humano baseado numa matriz cristã ou a relevância que o enfoque das Relações Humanas outorga à subjectividade individual não estão muito afastadas entre si. Sedas Nunes (1963), num artigo na 
Análise Social, manifestava a sua convicção nas virtudes das Relações Humanas, confirmando o interesse crescente das grandes empresas por este enfoque e referindo os foros nos quais estas ideias eram debatidas em Portugal (Instituto Nacional de Investigação Industrial, colóquios da Associação Industrial Portuguesa, Congresso de Saúde Mental ou encontros promovidos pelo Ministério das Corporações). Em suma, segundo o autor, o paradigma das Relações Humanas vinha corrigir os modelos científicos de produção - taylorismo ou fordismo - com a integração do mencionado factor humano.

Surgem, pois, os princípios de gestão e organização que incorporam nos seus postulados a subjectividade individual, tal e como definida pela psicologia. Como tal, à linguagem da economia e à lógica da utilidade e da eficiência promovidas pela tecnocracia somavam-se a linguagem da psicologia e a lógica da expressividade no marco da modernização do país. O grosso dos postulados das Relações Humanas chega à Europa graças aos peritos norte-americanos que exerciam funções de consultores e conselheiros no âmbito do Plano Marshall. Serão os franceses e os belgas os intermediários destes postulados, mediante o contacto com os quadros portugueses que vão para o estrangeiro para completar a sua formação (Gonçalves, 1991: 134). O processo de negociação para a integração de Portugal na Organização Europeia de Cooperação Económica também foi uma oportunidade para esses quadros dirigentes terem contacto com aqueles postulados (Gonçalves, 2006: 349). O eco dos mesmos deixa-se ouvir em diferentes foros. A Escola Superior de Organização Científica do Trabalho oferecia formação relativa às relações humanas para os futuros gestores e, como tal, na sua secção de psicologia eram administrados testes psicológicos destinados ao recrutamento e à orientação profissional (Bairrão, 1968). Por outro lado, a Revista do Gabinete de Estudos Corporativos (RGEC) incorporava alguns artigos sobre a temática das Relações Humanas e a sua ligação ao rendimento laboral, assim como a publicação Indústria Portuguesa (IP).$^{10}$ Encontramos novos exemplos, agora num artigo intitulado "Relações Humanas no Trabalho", publicado em 1960 na revista Indústria, no qual o autor, a partir de um estágio em França, reflecte sobre a necessidade de criar na empresa um ambiente de "valor para a pessoa humana", uma vez que, na sua opinião, a produtividade é influenciada qualitativa e quantitativamente por factores de "ordem humana" (Caldeira, 1960). Três anos antes, numa

${ }_{10}$ Por exemplo, Manuela Silva (1958), "Rendimento e escola de Relações Humanas”, RGEC, 34, ou, da mesma autora (1959), "Organização da empresa e rendimento económico", IP, 381, e "Organização formal e informal da empresa”, IP, 382. Confere Gonçalves (1991: 136). 
palestra promovida pelo Grupo Português da Associação Internacional de Orientação Profissional em Bruxelas, Mário Gonçalves Viana insistia na importância do bem-estar psicológico na vida da empresa: "sabe-se hoje [...] que toda a frustração provém da não satisfação de uma necessidade ou do desencontro de sentimentos, de volições e de paixões”. Daí derivaria o imperativo de formar no estrangeiro - dadas as insuficiências portuguesas neste campo - quadros nacionais especializados nestas matérias; e tornava-se "indispensável proporcionar a todos quantos se destinam às funções de liderança $[\ldots]$ conhecimentos substanciais de psicologia e de interpsicologia. A competência técnica deve ser completada por uma satisfatória compreensão dos valores humanos e sociais" (Viana, 1957: 16).

Constata-se, pois, a existência de um discurso à volta dos conhecimentos precisos para o bom desempenho dos labores de organização e gestão, que se traduz num tipo de literatura gerencial que informa acerca das inovações no terreno da direcção de organizações. ${ }^{11}$ Estes textos - palestras, livros, comunicações, relatórios... - vão dirigidos aos directores, responsáveis intermédios e administrativos, contendo receitas práticas para melhorar o rendimento da empresa. Para estes, a subjectividade individual deve ser integrada em qualquer sistema de gestão eficiente. Daí a importância concedida a essa subjectividade no domínio da coordenação de equipas de trabalho, no relacionamento com os subordinados, na liderança ou na obtenção de resultados. A literatura gerencial molda e reflecte o imaginário do gestor, do empreendedor, e reflecte um conjunto de imagens e representações que estruturam o discurso empresarial acerca da gestão e do sentido outorgado à própria gestão. Este imaginário vai evoluir de uma perspectiva quantitativista - a racionalização pormenorizada do trabalho em virtude da maximização dos lucros e da produtividade - até uma perspectiva não menos científica - apoiada na psicologia como disciplina -, que incorpora as emoções ou a motivação no terreno da gestão empresarial. A auto-ajuda possui uma estreita afinidade com esse discurso gerencial aberto à subjectividade individual e à dimensão psicológica da pessoa. A sua orientação para o mundo dos negócios, a sua atenção para com a personalidade, a persuasão e o sucesso pressupõem referências básicas para quem vise melhorar as suas prestações como gestor.

\footnotetext{
${ }^{11}$ A obra clássica que analisa esta literatura gerencial é Bendix (1974). Mais recentemente é de grande interesse Boltansky e Chiapello (2002). Para uma síntese sobre os estudos críticos de gestão, ver Fernández Rodríguez (2007).
} 


\section{Conclusão}

Em Portugal, a literatura de auto-ajuda começa a ganhar visibilidade a partir dos anos 1950. Neste tipo de textos, desenha-se um modelo de indivíduo orientado para o êxito, apostando na sua capacidade de autogoverno. Este facto foi identificado nestas páginas como o sintoma de uma racionalidade política liberal, que coexiste com a racionalidade política autoritária "estadonovista". Não obstante, o fenómeno da auto-ajuda é afim a outras tendências sociais que revelam a pretensão dos poderes estatais governarem tendo presente a possibilidade de autogoverno individual. Sendo assim, emerge um espaço genérico relativo à actividade económico-empresarial onde essa autogestão parece admissível, e no qual se começam a definir mentalidades tecnocráticas e novas concepções sobre a administração das organizações. Para além do autogoverno individual encontram-se os repertórios da economia e da psicologia, tal como acontece no caso da auto-ajuda. E é nesse "fogo cruzado" entre o utilitário e o expressivo, entre o económico e o psicológico, que se movimenta essa peculiar criatura que se autogoverna - o homem de êxito.

\section{Referências bibliográficas \\ Fontes primárias}

Atkinson, William Walker (1950), A força do pensamento na vida e nos negócios. Lisboa: Ailland [2. ${ }^{a}$ ed.; orig.: Thought-Force in Business and Everyday Life (1900). Chicago: The Psychic Research Company].

Carnegie, Dale (1952), Como fazer amigos e influenciar as pessoas, trad. de Fernando Tude de Sousa. Lisboa: Editorial dos Continentes [ed. orig.: How to Win Friends and Influence People (1936). New York: Simon and Schuster].

Marden, Orison Sweet (1926), Ajuda-te a ti mesmo, trad. de João Crisóstomo Lopes. Porto: Livraria Figueirinhas [ed. orig.: Be Good to Yourself (1910). New York: T.Y. Crowell and Co.].

Ramalho, Francisco (1961), Como melhor viver e ganhar mais dinheiro. Gráfica Eborense.

Rodrigues, F. Pereira (1945), Mandamentos da saúde, da civilidade, do triunfo. Lisboa: Empresa Gráfica.

Silveira, J. Fontana da (1953), Como triunfar no comércio. Porto: Livraria Progredior [2. ${ }^{a}$ ed.].

Torfs, Maurice (1942), A arte de triunfar. Lisboa: Livraria Portugalia, trad. de João Paulo Freire [L'efficience en vingt leçons (1933). Bruxelles: La revue de L'efficience]. 


\section{Fontes secundárias}

Ampudia de Haro, Fernando (2006), "Administrar el yo: literatura de autoayuda y gestión del comportamiento y los afectos, Revista Española de Investigaciones Sociológicas, $113,49-75$.

Ampudia de Haro, Fernando (2010a), "El logro del éxito: la dimensión social de la literatura de autoayuda”, Revista Española de Sociología, 13, 11-30.

Ampudia de Haro, Fernando (2010b), "Recivilizar España y Portugal. El arquetipo humano franquista y salazarista”, Historia Actual, 8, (no prelo).

Bairrão, Joaquim (1968), "O ensino da Psicologia em Portugal: situação e perspectivas”, Análise Social, 22-23-24, 730-762.

Barreto, António (2004), “Mudança social em Portugal, 1960-2000”, in António Costa Pinto (coord.), Portugal Contemporâneo. Lisboa: Dom Quixote.

Bellah, Robert et al. (1989), Hábitos del corazón. Madrid: Alianza.

Bendix, R. (1974), Work and Authority in Industry. Berkeley University of California Press.

Boltanski, L.; Chiapello, E. (2002), El nuevo espíritu del capitalismo. Madrid: Akal.

Brito, José M. Brandão (1989), "Os engenheiros e o pensamento económico do Estado Novo”, in José Luís Cardoso (org.), Contribuições para a bistória do pensamento económico em Portugal. Lisboa: Dom Quixote.

Burchell, Graham (1993), "Liberal Government and Techniques of the Self", Economy and Society, 22-3, 267-283.

Caldeira, Raul (1960), "Relações humanas no trabalho. Notas de um estágio em França”, Indústria, 2 (separata).

Cravinho, João (1969), "Fundamentos das decisões de planeamento em Portugal”, Análise Social, 27-28, 420-446.

Dean, Mitchell (2002), "Liberal Government and authoritarianism”, EconomyESociety, 31-1, 37-61.

Durán Muñoz, Rafael (1997), “A crise económica e as transições para a democracia: Espanha e Portugal em perspectiva comparada”, Análise Social, 141, 369-401.

Fernandes, Tiago (2005), Nem ditadura nem revolução. A Ala Liberal e o Marcelismo 1968-1974. Lisboa: Dom Quixote.

Fernández Rodríguez, Carlos (2007), El discurso del Management: tiempo y narración. Madrid: CIS/Siglo XXI.

Gonçalves, Carlos Manuel (1991), “A construção social dos quadros nos anos 60: algumas perspectivas de análise”, Revista da Faculdade de Letras da Universidade do Porto, 1, 101-164.

Gonçalves, Carlos Manuel (2006), Emergência e consolidação dos economistas em Portugal. Porto: Afrontamento.

Grácio, Rui (1990), “A expansão do sistema de ensino e a movimentação estudantil” in António Reis (org.), Portugal Contemporâneo, vol. 5. Lisboa: Alfa. 
Hyndess, Barry (1997), Disertaciones sobre el poder. De Hobbes a Foucault. Madrid: Talasa.

Illouz, Eva (2007), Intimidades congeladas. Las emociones en el capitalismo. Buenos Aires/Madrid: Katz Editores.

Lamo de Espinosa, Emilio et al. (1994), La sociología del conocimiento y de la ciencia. Madrid: Alianza.

Marinis, Pablo de (1999), "Gobierno, gubernamentalidad, Foucault y los anglofoucaltianos (O un ensayo sobre la racionalidad política del neoliberalismo), in Ramón Ramos e Fernando García (orgs.), Globalización, riesgo, reflexividad. Tres temas de la teoría social contemporánea. Madrid: CIS.

Nunes, Adérito Sedas (1963), “As relações humanas: significado e deturpações”, Análise Social, 1, 104-113.

Nunes, Adérito Sedas (1968), Sociologia e ideologia do desenvolvimento. Lisboa: Moraes Editores.

Papalini, Vanina (2008), La formation de la subjectivité dans la cultura contemporaine: le cas des libres de bien-etrê. Tese de Doutoramento, Dpto. Comunicação, Universidade de Paris 8.

Passos, Marcelino Lyra (1990), "A discussão sobre a reforma administrativa nos finais do Estado Novo: um exemplo da incapacidade de reforma do Caetanismo", in Actas do I Congresso Português de Sociologia. Lisboa: APS-Fragmentos.

Rosas, Fernando (1994), “O Estado Novo”, in José Mattoso (org.), História de Portugal, vol. 7. Lisboa: Estampa.

Rose, N. (1990), Governing the Soul. The Shaping of the Private Self. London: Routledge.

Rose, N. (1997), "El gobierno de las democracias liberales avanzadas: del liberalismo al neoliberalismo", Archipiélago, 29, 25-40.

Rose, Nikolas e Miller, Peter (1992), "Political Power beyond the State: Problematics of Government", The British Journal of Sociology, 43(2), 173-205.

Valverde, Mariana (1996), "Despotism and ethical liberal governance", Economy $\varepsilon$ Society, 25(3), 356-372.

Vázquez García, Francisco (2005), Tras la autoestima. Variaciones sobre el yo expresivo en la modernidad tardía. San Sebastián: Tercera Prensa.

Viana, Mário Gonçalves (1957), "Relações humanas na vida da empresa”, Revista de Contabilidade e comércio, 25 (separata). 